\title{
PROCESSOS DE RACIALIZAÇÃO: \\ Inteligibilidade, Hibridade e Identidade Racial em Evidência
}

\author{
RACIALIZATION PROCESSES: \\ Intelligibility, Hybridity and Racial Identity in Evidence
}

Eloisio Moulin de Souza

Universidade Federal do Espírito Santo

eloisiomoulin@gmail.com

Submissão: $11 / 07 / 2017$

Aprovação: 13/11/2017

\begin{abstract}
RESUMO
Este artigo visa analisar as inteligibilidades sobre raça produzidas pelos processos de racialização nos alunos de graduação em administração de uma universidade federal. Para atingir este objetivo foram realizados grupos focais com alunos de graduação em administração, utilizando-se a análise do discurso como forma de análise dos dados produzidos. As análises foram realizadas e fundamentadas pelas lentes conceituais fornecidas pela abordagem pós-colonial em uma perspectiva construcionista social de raça para se entender o que significa raça para os alunos e como as fronteiras entre diferentes raças são construídas e descontruídas. Nesse sentido, a inteligibilidade hegemônica sobre raça está baseada em características fenotípicas, principalmente cor de pele. Entretanto, outras inteligibilidades também foram encontradas. Apesar de utilizarem características fenotípicas na definição de raça, os alunos evidenciam em seus discursos as formas pelas quais elementos fenotípicos são politicamente utilizados para mascarar opressões, hierarquias sociais, desigualdades e aspectos históricos relacionados a construção de raça no contexto brasileiro, rompendo com a lógica essencialista de que haveria uma raça original e essencial.
\end{abstract}

Palavras-chave: Raça. Inteligibilidade. Racialização. Hibrido. Identidade. 


\begin{abstract}
This article aims to analyze the intelligibilities about race produced by the processes of racialization in undergraduate students in management of a federal university. To achieve this goal, focus groups were held with undergraduate students in management, using discourse analysis as a way of analyzing the data produced. The analyzes were carried out and grounded by the conceptual lenses provided by the postcolonial approach in a constructional social perspective of race to understand what race means to the students and how the boundaries between different races are constructed and deconstructed. In this sense, hegemonic intelligibility about race is based on phenotypic characteristics, mainly skin color. However, other intelligibilities were also found. Although they use phenotypic characteristics in the definition of race, the students evidence in their discourses the ways in which phenotypic elements are politically used to mask oppression, social hierarchies, inequalities and historical aspects related to the construction of race in the Brazilian context, breaking with the essentialist logic of that there would be an original and essential race.
\end{abstract}

Keywords: Race. Intelligibility. Racialization. Hybrid. Identity.

\title{
1 INTRODUÇÃO
}

Existe um silenciamento da área de administração em relação ao estudo de raça nas organizações. Isto ocorre tanto no Brasil (CARNEIRO, 2005; ROSA, 2014; VIEIRA; CALDAS, 2005) quanto em outras partes do globo (COX; NKOMO, 1990; HARDING; FORD; FOTAKI, 2013; HOLVINO, 2010; ELY; MEYERSON, 2000; JONES; STABLEIN, 2006; KONRAD, 2003; PRASAD, 2006). A despeito de raça ser algo evidente e visível, principalmente em sociedades em que a construção de raça é fundamentada em características fenotípicas, raça ainda é um aspecto segregado, negado e evitado nas organizações (ACKER, 2006), embora as mesmas também atuem nos processos de racialização e classificação social (KALONAITYTE, 2010). Exatamente buscando contribuir com este debate este artigo tem como principal objetivo analisar as inteligibilidades constituídas sobre raça pelos alunos de graduação de administração de uma universidade. A principal relevância deste artigo está em promover o debate sobre raça, buscando assim diminuir as lacunas de pesquisa sobre aspectos raciais em organizações na área de administração. Além disso, este artigo traz novas contribuições ao debate sobre raça ao utilizar o conceito de inteligibilidade desenvolvido por Butler (1990, 1993a) em conjunto com os conceitos pós-coloniais de Bhabha (1990, 1994, 1996, 1998); Hall (1993, 1996) e Anzaldúa (1987).

Para tanto, realizou-se grupos focais com alunos de graduação em administração com a principal intenção de se compreender os discursos produzidos sobre raça. Os enunciados pelos quais os alunos expressam o que é raça manifestam as relações de poder e os discursos que os atravessam e constituem suas inteligibilidades e sentidos sobre raça. Este processo discursivo pelo qual sentidos e significados sobre raça são produzidos e ganham inteligibilidade é denominado de racialização. Portanto, entender a inteligibilidade que os alunos de administração têm sobre raça propicia analisar as especificidades históricas, sociais, políticas e econômicas que contingenciam a inteligibilidade sobre raça, revelando como raça é constituída no contexto brasileiro. Desta forma, apesar da inteligibilidade sobre raça se apoiar em aspectos corporais e biológicos, raça não é uma propriedade dos corpos em si (GILROY, 2001; SANSONE, 1996; SWAN, 2010), mas uma construção discursiva sobre corpos 
produzida por meio de relações e interações sociais complexas (ACKER, 2011; SCHWARCZ, 2001; BAINES, 2010). O estudo do processo de racialização permite evidenciar as relações de poder que constituem a inteligibilidade sobre raça, bem como demonstrar a atuação de raça como um dispositivo organizador e produtor de hierarquias sociais.

Assim, para cumprir este intento, o próximo tópico do artigo propõe debater sobre as diferentes formas de se entender e analisar raça, contrapondo-se principalmente a abordagem genealogista/primordialista à perspectiva construcionista de raça, sendo que a abordagem construcionista é empregada neste artigo como referencial teórico no processo de análise dos dados produzidos. Em seguida conceitos pós-coloniais sobre identidades de raça são discutidos, procurando-se romper com a noção essencialista, universal e originária de raça. $\mathrm{O}$ tópico seguinte descreve os caminhos percorridos durante a produção dos dados da pesquisa empírica realizada. Posteriormente, os conceitos trabalhados no referencial teórico são utilizados, confrontando-os com os dados produzidos, para se efetuar a análise dos mesmos, utilizando-se a análise do discurso (AD) como principal ferramental para realização da análise. Por fim, as principais conclusões da pesquisa são evidenciadas nas considerações finais do artigo.

\section{A ABORDAGEM CONSTRUCIONISTA DE RAÇA}

Os estudos sobre raça podem ser descritos em duas grandes abordagens: genealogista e construcionista. A perspectiva genealogista busca entender a evolução humana na natureza e sua relação com o desenvolvimento das sociedades, sendo ela a grande responsável de como o senso comum entende raça nos dias atuais. Para os genealogistas as diferenças sociais e de desenvolvimento entre sociedades tem relação direta com aspectos físicos e biológicos, em que raça passa a significar uma categoria de humanos equivalente à categorização de espécimes: brancos (Europeus), negros (Africanos), vermelhos (nativos norte-americanos) e amarelos (Asiáticos); além de criar uma hierarquia entre raças pela qual o branco é visto como superior (PROUDFORD; NKOMO, 2006). Devido à abordagem genealogista, geralmente os sentidos e significados sociais produzidos sobre raça equivocadamente nos remetem à ideia de que raça é um conceito meramente biológico, fixo, estável e genético, portanto, algo limitado ao campo da natureza com uma existência a priori. A abordagem genealogista de raça emerge nas ciências sociais com o nome de primordialismo, que tem como principal expoente Clifford Geertz (MUCK, 2011).

Contemporaneamente o conceito de raça rompe com esta definição biológica e se constitui como um conceito sócio-histórico. Raça é uma construção social e, assim sendo, um conceito que deve considerar aspectos políticos, sociais, econômicos, culturais e históricos em sua definição, ou seja, o significado de raça está para além de sangue biológico. Desta forma, raça é um conceito que nos remete a relações sociais e apresenta-se como um conceito útil para a análise e a descrição destas relações sociais (SCHWARCZ, 2001), pois raça é uma identidade sobre a qual seres humanos são diferenciados, classificados e hierarquizados (GILROY, 2001). Portanto, a primazia biológica defendida pelos genealogistas/primordialistas é colocada em cheque pelos construcionistas os quais consideram raça uma construção social contingenciada por relações de poder. Para o construcionismo raças existem não por razões biológicas, mas porque são criações sociais que dividem, hierarquizam e categorizam pessoas através de características genotípicas ou fenotípicas como sangue ou cor de pele, ou seja, raça é uma invenção humana criada com 
objetivos sociais e políticos que intentam organizar a sociedade por meio de dominação e opressão (APPIAH, 1985; DuBOIS, 1970). Vale ressaltar que diferentes formas de divisão social (raça, classe, gênero, etnia) têm um ponto em comum: a tendência de serem naturalizadas, ou seja, de serem consideradas como um produto biológico (COHEN, 1988).

Em outras palavras, aquilo que a princípio se apresenta como materialmente natural e biológico deve ser entendido como uma construção discursiva (ANZALDÚA, 1987), pois "'raça' refere-se a diferenças definidas socialmente fundamentadas em características físicas, culturais, e opressões e dominações históricas, justificadas por crenças arraigadas" (ACKER, 2006, p. 444, grifos originais, tradução nossa). Assim, raças são relações, práticas e sistemas de significação que permeiam e estruturam a sociedade, produzindo hierarquias e desigualdades (ACKER, 2011). Portanto, raças são grupos historicamente e culturalmente definidos com a finalidade de produzir identidades raciais com uma intencionalidade estratégica que visa legitimar desigualdades (LETICHE, 2009). Raça não tem apenas um significado social, mas também carrega consigo uma verdade ontológica que atua como um princípio organizador do social (DuBOIS, 1970), ou seja, raça é um aspecto identitário mutável e fluído construído por meio de interações sociais complexas, ideológicas e culturais (BAINES, 2010) que produz no imaginário social a noção de que raça sempre existiu e que é natural e biológica (DuBOIS, 1970).

Portanto, raça refere-se a diferenças sociais e culturais, geralmente justificadas, encobertas, fundamentadas e marcadas por diferenças físicas, como cor de pele e tipo de cabelo, mas que de fato estão enraizadas e são construídas por diversas práticas sociais, culturais, econômicas e ideológicas (ACKER, 2011; APPIAH, 1985), ou seja, apesar de osso, cabelo, pele e sangue serem os referentes primários em um discurso racial (GILROY, 2001), raça não é uma propriedade natural que pertence a certos tipos de corpos, mas antes uma construção discursiva, social e histórica envolta por relações de poder sobre corpos, pois os sentidos produzidos relacionados à cor de pele não é uma propriedade do corpo, mas sim um produto de relações sociais complexas (SANSONE, 1996; SWAN, 2010). Racialização é o nome dado a este processo de construção social de raças. O conceito de racialização rompe com os padrões estabelecidos e legitimados que concebem raça como sendo uma simples característica determinada pela biologia dos corpos ao mesmo tempo em que rompe com a visão de que raça teria alguma essência (GILROY, 2001), enfatizando o caráter histórico, político, cultural, econômico e social na construção de sujeitos racializados. Portanto, o conceito de racialização declara que raça não é determinada pela biologia (GILROY, 2001), apesar de se apoiar nela para justificar as relações de poder estabelecidas neste processo, intentando com isso camuflar todo o seu conteúdo político.

Assim, racialização são processos discursivos por meio dos quais sentidos e significados raciais são estabelecidos e adquirem inteligibilidade. Dentro dos jogos de verdade a racialização estabelece a ordem do discurso descrita por Foucault (1970) em relação à raça. A racialização controla, seleciona e organiza a produção do discurso, sentidos e inteligibilidade que temos sobre raça. Portanto, racialização é o "termo usado para descrever processos sociais, culturais, econômicos e psicológicos que fazem raça importante e as formas que raça é usada como uma base para desigualdade e discriminação" (SWAN, 2010, p. 667), sendo que o principal produto do processo de racialização é a classificação de pessoas em categorias raciais e a criação de hierarquias entre estas categorias. É somente dentro do discurso e submetendo-se a seus limites, normas e condições que o sujeito pode adquirir significado e inteligibilidade. $O$ discurso é constitutivo e não meramente representativo de uma cultura, portanto, formativo e não meramente expressivo de subjetividades, identidades e políticas (HALL, 1996). 
O racismo deve ser entendido como um processo de racialização que opera construindo raças e fronteiras simbólicas entre categorias socialmente criadas dentro de um sistema binário que intenta marcar, fixar e naturalizar as diferenças (HALL, 1996). Para Guillaumin (1995) o racismo tem sua emergência na história do Ocidente entre os séculos XVIII e XIX durante a expansão colonial, adquirindo seu caráter ideológico no século XIX na Europa. Neste contexto inicia-se todo um debate de como classificar essas civilizações, emergindo durante os séculos dezoito e dezenove uma ideologia de raça fundamentada, ao mesmo tempo, no senso comum e na ciência da época para autorizar e espalhar as bases e abusos de raça, dando passagem à exploração colonialista baseada na classificação, hierarquização e naturalização racial com o intuito de controlar populações (GUILLAUMIN, 1995; PRASAD, 2006; WALTON; CALIENDO, 2011). Neste processo de racialização o ocidente é o Sujeito escrito em maiúsculo (ocidente entendido como significando apenas Europa), enquanto o sujeito colonial é o Outro que possui uma subjetividade precária (SPIVAK, 1988). Nesta relação, o Sujeito Europa manifesta sua superioridade ao propagar para as civilizações atrasadas suas leis, políticas, modelos econômicos, costumes e ideologias, sempre vistos como perfeitos e superiores (KALONAITYTE, 2010; PRASAD, 2006), pois para existir o civilizado tem que haver o selvagem (BHABHA, 1990). O conceito de raça foi construído para resolver a contradição crescente entre direitos individuais, liberdade e a prática da escravidão, ou seja, "raça e etnicidade são construções sociais com origens claramente coloniais" (MUCK, 2011, p. 29, tradução nossa). O poder colonial e imperial confeccionou códigos raciais que constituíram a ideologia racista vigente (GILROY, 2001; GUILLAUMIN, 1995).

O processo de racialização colonial no Brasil foi fortemente influenciado pela aparência física, sendo denominado por Nogueira (2007) de preconceito de marca. Nesta lógica, o parentesco e ascendência não são determinantes no processo de racialização, pois as pessoas são classificadas racialmente em razão do fenótipo, ou seja, de sua aparência física como cor de pele e cabelo, por exemplo. Diferentemente do preconceito de marca, no preconceito de origem, manifesto, por exemplo no one drop blood estabelecido nos Estudos Unidos, a classificação racial de uma pessoa é genotípica, ou seja, uma pessoa pode ser classificada como negra independentemente de sua aparência física e do grau de mestiçagem da mesma, pois a simples presença de um ancestral negro determina sua raça como sendo negra, mesmo que a pessoa tenha pele branca e olhos azuis (NOGUEIRA, 2007; ROSA, 2014). No caso brasileiro o alto grau de miscigenação fez com que o processo de categorização racial se torne mais complexo, fazendo com que a escolha de uma raça não seja um processo fácil e com que muitos sujeitos se identifiquem como bi-raciais (PROUDFORD; NKOMO, 2006). Além disso, a identidade racial no Brasil é bastante fluída com o estabelecimento de diversas categorias raciais em função das características físicas, principalmente cor de pele, o que não gera base para o desenvolvimento de uma política segregacionista. $\mathrm{O}$ alto grau de miscigenação no Brasil contribui para criar o mito de que haveria uma grande mobilidade social no contexto brasileiro denominado por Degler (1971) de escotilha de escape mulato (mulatto escape hatch), pois a alta miscigenação racial brasileira gerou a possibilidade de não se ser branco nem negro, mas mulato. A miscigenação foi, inclusive, incentivada no Brasil, pois se acreditava na miscigenação como forma de regeneração social dos negros (LACERDA, 1912). Os defensores da miscigenação acreditavam que negros e mestiços representavam raças atrasadas e inferiores e que somente a miscigenação constante com brancos poderia promover $o$ branqueamento e, consequentemente, a evolução destas raças (SCHWARCZ, 2012). 
Aspectos históricos, sociais e culturais aliados ao alto grau de miscigenação fizeram com que o conceito de raça adquira contornos específicos no Brasil, gerando principalmente uma crença segundo a qual existiriam raças originais e raças não originais, frutos da miscigenação. As abordagens pós-coloniais procuram exatamente problematizar esta concepção colonial de raça, rompendo com a noção essencialista de que haveriam raças originárias e essenciais. Assim, o próximo tópico busca exatamente trazer o debate póscolonial sobre este tema.

\section{PÓS-COLONIALISMO: FRONTEIRAS, HIBRIDADE E INTELIGIBILIDADE}

Divisões raciais são construídas em torno de fronteiras excludentes e includentes produzidas de forma permutável e maleável em diferentes extensões que dividem pessoas entre nós e eles (YUVAL-DAVIS, 2006). Assim, negro, por exemplo, não pode ser entendido como uma questão biológica apenas, mas negro deve ser entendido como um termo aglutinador de uma experiência comum de racismo e marginalização (HALL, 1996). Por isso Hall (1996) afirma que o sujeito negro não é estabilizado por uma natureza ou por qualquer garantia essencial, pondo fim a uma noção inocente de que existe uma essência do sujeito negro fundamentada em características físicas. Assim, não existe o puro/original tanto na cultura negra quanto na cultura branca (HALL, 1993). Além disso, Bhabha (1990, p. 210, tradução nossa) acrescenta que "hibridade colonial não é um problema de genealogia ou identidade entre duas culturas diferentes", pois todas as raças, independentemente da existência de miscigenação ou não, são consideradas hibridas para Bhabha (1990, 1994), ou seja, o híbrido é constituído como não sendo um original. Assim, “o 'original' nunca está por si só finalizado ou completo. $\mathrm{O}$ ‘originário' está sempre aberto a tradução de modo que nunca se pode dizer que tenha um momento anterior totalizado de ser ou significar - uma essência" (BHABHA, 1990, p. 210, grifos originais, tradução nossa).

Entretanto, o hibrido não significa a emergência de uma outra e nova categoria fundacional de sujeito, ou seja, o híbrido não é uma nova identidade racial (BHABHA, 1990). Da mesma forma o hibrido também não é fruto da biologia, ou uma mistura genética de raças diferentes, pois não existem híbridos biológicos. Híbridos são produções identitárias fragmentadas, interacionais e discursivas e não cruzamentos biológicos (TATE, 2005). Assim, híbrido significa que as identificações e os posicionamentos identitários dos sujeitos são híbridos e não significa o fruto de um cruzamento biológico ou cultural. $\mathrm{O}$ híbrido nega o essencialismo pelo qual existe a priori culturas ou identidades originais, no qual o híbrido seria apenas o produto do cruzamento de culturas originais prévias. Todas as culturas e identidades estão sempre em processo continuo de hibridade (BHABHA, 1990). Hibridade é "uma identificação que surge na luta pela posição dentro dos discursos. É constituído por discursos de eu/outro e também vem constituir esses discursos" (TATE, 2005, p. 25, tradução nossa). Entretanto, a identificação sempre é incompleta, produzindo seres humanos incompletos (BENDL; FLEISCHMANN, 2008; COOPER, 2001). Assim, todas as identidades raciais são mutáveis e não essenciais, produzindo sempre um sujeito cuja existência é incompleta e precária. Entretanto, dentro de uma lógica binária somente algumas formas de existências identitárias raciais é que serão consideradas falhas como negros e índios (LASTA; HILLESHEIM, 2014). Enfim, o híbrido não é "capaz de traçar dois momentos originais do qual o terceiro emerge, ao invés hibridade para mim é o 'terceiro espaço' o qual capacita outras posições emergirem" (BHABHA, 1990, p. 211, grifos originais). Desta forma, o terceiro espaço e o híbrido não são uma identidade e devem ser entendidos como um 
processo contínuo sempre em movimento. O terceiro espaço deve ser entendido como um catalizador e capacitador da alteridade, ou seja, o terceiro espaço é o processo de negociação de posicionamento da identidade no discurso (TATE, 2005). A hibridade é, ao mesmo tempo, rompimento e uma reconciliação com a noção de uma identidade essencial, pois a hibridade produz, simultaneamente, diferença e igualdade (YOUNG, 1995).

A hibridade adquire um sentido para Bhabha que não significa multiculturalismo, pois o híbrido para o autor não é a junção de duas identidades originais que produziria uma terceira identidade, uma vez que não existem identidades originais. Portanto, não existe um negro ou branco originais que se cruzariam e formariam uma terceira raça denominada de híbrido. Branco e negro não possuem uma essência e se constituem mutuamente produzindo diferenças pelas quais um contém o outro. Somente em uma visão essencialista existe um original da identidade (BHABHA, 1990). A essencialização de raça naturaliza e torna ahistórica as diferenças, confundindo e mascarando o que é histórico e cultural como sendo natural, biológico e genético (HALL, 1993). A perspectiva de unidade essencial de uma raça em particular tornou-se ainda mais contestada por acreditar na ideia de que existe uma identidade fundamental compartilhada por todos os membros de um grupo (GILROY, 2001). A busca de uma cultura e raça originais e puras essencializa a diferença em uma relação binária entre tradições culturais deles versus nossas de uma forma que cada polo é considerado exclusivo, autônomo e autossuficiente (HALL, 1993). Somente através da naturalização da raça e da exclusão das diferenças internas presentes em uma mesma categoria identitária racial é que a estabilidade, universalidade e unidade podem existir (TATE, 2005). Além do essencialismo biológico deve-se evitar também outras formas de essencialismos, sejam elas nacionalistas, culturais ou econômicas (GILROY, 2001). Assim, raça é um lugar constituído pela linguagem, cultura e história que atuam na produção de identidades e das subjetividades, pois todo discurso é posicionado, situado, localizado e contextual (HALL, 1996). Uma abordagem primordialista não consegue explicar a fluidez e multiplicidade dentro de uma mesma cultura. Por isso Bhabha (1994), em uma perspectiva pós-colonial, defende que etnia é uma atividade de copiar e colar pela qual sujeitos escolhem quais partes de sua identidade desejam salientar e quais não, ao invés de algo homogêneo dentro de uma mesma cultura.

Para Anzaldúa (1987) existem fronteiras (que podem ser físicas/geográficas, psicológicas, sexuais e espirituais) presentes em todos os lugares pelas quais as diferenças se afetam. Ou seja, as fronteiras são espaços "onde duas ou mais culturas beiram uma a outra, onde pessoas de diferentes raças ocupam o mesmo território, onde as classes mais baixas, baixas, médias e altas se tocam" (ANZALDÚA, 1987, p. 17). As fronteiras criam e são criadas pelo espaço, consciência, tradição e experimentação. Fronteiras são territórios que se estendem em todas as direções a partir de sua borda ou seu limite. Fronteira é a borda pela qual dois elementos se tocam e ao mesmo tempo se separam, borrando os limites de forma que não exista mais este ou aquele lado (TYLER, 2009). Por exemplo, a cor marrom clara da pele do mulato torna obscura e dúbia a pele como significante racial, fazendo com que o mulato não seja nem negro nem branco. O mulato é uma negociação discursiva de posição de identidade que sinaliza que ele não é exatamente negro, mas ocupa um espaço in-between (BHABHA, 1994, 1996; TATE, 2005). Tyler (2009) destaca que apesar de o binário facilitar o estabelecimento de fronteiras, a fronteira por si só não pode ser descrita e nem seve ao binário, pois as fronteiras têm como principal característica dissolver e não dominar dualidades. Fronteiras são lugares onde o espaço entre dois indivíduos diminuem com a intimidade (ANZALDÚA, 1987), produzindo novas conexões e possibilitando constantes transformações e modificações de ambos os lados, conectando uns aos outros, ou seja, 
fronteiras são coalizões culturais capazes de produzirem novas histórias (ANZALDÚA, 1987), "Migrando pelos entre-lugares da diferença, mostra como esta é constituída na história e adquire forma a partir de articulações sempre locais - suas mestiçagens múltiplas revelam simultaneamente mecanismos de sujeição e ocasiões para o exercício da liberdade" (COSTA; ÀVILA, 2005, p. 694).

A noção de existência de fronteiras entre identidades pode nos remeter à ideia de que alguma origem ou essência identitária permanece (TATE, 2005). Entretanto, identificações são atos performativos produzidos pela reiteração constante do poder de um discurso que produz um fenômeno que ele mesmo regula e constitui (BUTLER, 1993b). Sendo raça um discurso produzido por processos de racialização, as identificações e as desidentificações raciais são atos performativos pelos quais um "sujeito traz em si para se tornar um sujeito aquilo que o nomeia" (TATE, 2005, p. 92). Em termos raciais, políticas de pele, raça e ancestralidade/parentesco são fundamentais para os processos discursivos de racialização. Entretanto, esta não é uma relação determinística, pois apesar de a cor da pele afetar a identificação, desidentificação e reconhecimento para se afirmar a raça de um sujeito, esta não é uma relação que, por si só, determina o nível de identificação racial de um sujeito com uma raça (TATE, 2005), contrariando também a lógica do one drop blood, que assume identificação de raça como uma questão apenas de parentesco.

Assim, discursos são fronteiras sociais que definem o que pode ser dito, o que é inteligível e os sentidos produzidos, não sendo possível escapar do discurso, pois ele constitui a visão que temos sobre algo, definindo a realidade. $\mathrm{O}$ discurso produz os sentidos que temos sobre algo, mas ele não é uma propriedade que pertence aos sujeitos e não tem um significado essencial, podendo ser ressignificado (BENDL, 2005). Identidades são fluídas e produzidas por processos sociais de racialização, sexualização e generificação (BENDL; FLEISCHMANN, 2008). O discurso manifesta a matriz de inteligibilidade sobre raça e atua como um plano que forja o sujeito por meio da repetição constante de normas discursivas racializadas (BUTLER, 1990, 1993a, 1993b). Indivíduos tornam-se sujeitos ao ocupar o lugar no discurso, ou seja, o sujeito é uma posição no discurso, assim, ele emerge como um lugar (BUTLER, 1997; TATE, 2005). Desta forma, o sujeito somente adquire inteligibilidade no momento que ocupa um lugar na linguagem, só se tornando inteligível quando se submete ao discurso. Portanto, o sujeito racial é uma ocasião linguística para que o indivíduo possa realizar, reproduzir e adquirir inteligibilidade (BUTLER, 1997). Categorias raciais garantem uma existência social reconhecível e durável. Assim, a adoção de tais categorias é preferível do que não se existir como sujeito (BUTLER, 1997).

\section{CAMINHOS PERCORRIDOS}

A produção de dados junto aos alunos foi realizada por meio de grupo focal. Segundo Godim (2003) os grupos focais coletam dados por meio das interações grupais. Como técnica, eles ocupam uma posição intermediária entre entrevistas em profundidade e observação participante. Segundo a autora os grupos focais são recursos que permitem compreender os processos de construção das percepções e atitudes de grupos humanos. Para Godim (2003) o moderador do grupo focal ocupa uma posição de facilitador da discussão e atem-se a formação de opiniões sobre um tema previamente determinado, no nosso caso, a inteligibilidade sobre raça e produção de identidades raciais. Os sujeitos da pesquisa foram alunos do curso de graduação em administração de uma Universidade Federal. Realizou-se seis grupos focais com participação total de 38 alunos, sendo que havia nos grupos focais 
alunos cotistas (15 alunos) e não cotistas (23 alunos). Em termos de raça 20 alunos se autodeclararam de raça branca; 8 alunos autodeclararam ser de raça negra; 7 de raça parda; 1 aluno de raça mestiça; 1 aluno de raça índia/amarela; e, 1 aluno se autodeclarou de raça humana.

Os grupos focais foram filmados e gravados para posteriormente se utilizar as filmagens e gravações no processo de análise dos dados produzidos. O tempo total de filmagem dos seis grupos focais foi de 514 minutos. Todos os grupos focais foram transcritos para facilitar as análises. Os alunos receberam denominações aleatórias para manter o anonimato dos mesmos. Desta forma, todos os alunos foram denominados pela letra $\mathrm{E}$ de Entrevistado seguido de numeração de 1 até 38. Portanto, os alunos receberam denominações iniciando em E1 até E38. Os dados produzidos foram analisados utilizando-se a análise do discurso (AD). A análise do discurso é um método adequado para estudar identidades ao enfatizar que os processos identitários são culturais, sociais e coletivos, ao invés de um fenômeno individual (AINSWORTH; HARDY, 2004). "Por esse tipo de estudo se pode conhecer melhor aquilo que faz do homem um ser especial com sua capacidade de significar e significar-se. A Análise de Discurso concebe a linguagem como mediação necessária entre o homem e a realidade natural e social" (ORLANDI, 2005, p. 15). Segundo Castro (2009, p. 117) o discurso é "o conjunto de enunciados que provém de um mesmo sistema de formação. [...] O discurso está constituído por um número limitado de enunciados para os quais se pode definir um conjunto de condições de existência”. Foucault $(1970,2010)$ acredita que, de uma forma geral, o discurso constitui e é constituído pelo mundo social. Assim, Foucault não enxerga o discurso e o próprio homem como algo pronto, acabado, fixo e estático, nem como possuindo uma essência.

Foucault (2010) acredita que o discurso e os saberes que se veiculam por meio dele não são neutros, mas constituídos por relações de poder que produzem categorias e hierarquias sociais não só entre os saberes, mas também entre os sujeitos. Para o autor, de fato não existe o discurso como uma substância que tem existência a-priori, mas sim uma função discurso, ou seja, o discurso é uma função e não um objeto dado. Desta forma, o discurso pode exercer diversas funções ao mesmo tempo, podendo atuar como funções políticas, econômicas, sociais, entre outras. A análise do discurso é uma abordagem de análise adequada para a pesquisa realizada neste artigo exatamente porque se busca entender a significação e os sentidos relacionados a identidades raciais produzidos nos alunos de administração, permitindo evidenciar a mediação entre linguagem e a realidade socialmente construída em relação à raça, salientando as condições de existência para que os indivíduos possam se tornar sujeitos portadores de uma determinada raça.

Foucault (1970) não estabelece e não descreve uma técnica de como se realizar a análise do discurso. $\mathrm{O}$ autor afirma que a análise do discurso desenvolvida por ele não é fundamentada na linguística nem na gramática. Portanto, diante do exposto, a análise de discurso empregada neste artigo teve como fundamento os seguintes procedimentos: (1) primeiramente, buscou-se analisar os processos de rarefação do discurso pelos quais inteligibilidades raciais são construídas e adquirem materialidade por meio do contingenciamento e controle das posições raciais que os sujeitos podem ocupar no discurso (FOUCAULT, 1970), processos estes denominados de racialização; (2) em seguida, foi analisada a incompletude e ambiguidade das posições discursivas ofertadas pelas quais os indivíduos podem existir como sujeitos possuidores de uma determinada raça, rompendo com a lógica essencialista de identidade. 


\section{A CONSTRUÇÃO DE RAÇA: UMA ANÁLISE DOS DISCURSOS DOS ALUNOS DA ADMINISTRAÇÃO}

Raças são construções sociais envoltas por relações de poder que fazem circular discursos sobre identidades raciais. Estes processos de construção de identidades de raça são denominados de racialização (GILROY, 2001; HALL, 1996; SWAN, 2010). Portanto, todo processo de racialização é histórico, político, cultural, econômico e social. A própria lógica hegemônica e naturalizada de raça como algo meramente biológico é, por si só, um produto dos processos de racialização em uma estratégia política de essencialização e naturalização das raças. Desta forma, o processo de racialização produz uma ordem do discurso (FOUCAULT, 1970) sobre a definição do que é raça, ao mesmo tempo controlando e fornecendo possiblidades de existências subjetivas racializadas, constituindo uma inteligibilidade social sobre o que se entende em relação ao significado de raça (BUTLER, 1990; 1993b). Indivíduos são tornados sujeitos possuidores de uma raça quando passam a ocupar uma posição nesta ordem discursiva através de processos de identificação e reconhecimento, transformando o indivíduo em um sujeito inteligível (ANZALDÚA, 1987; BUTLER, 1997; TATE, 2005). Assim, os próximos tópicos do artigo objetivam analisar os processos de racialização e a construção de identidades raciais no contexto brasileiro a partir dos discursos dos alunos de administração. Primeiramente, será analisada a inteligibilidade produzida nos alunos de administração sobre raça para, em seguida, debater a miscigenação racial no contexto brasileiro e a incompletude de raça.

\subsection{Inteligibilidade de raça e os processos de racialização}

Encontrou-se heterogêneas inteligibilidades sobre raça. Entretanto, a inteligibilidade hegemônica que os alunos manifestam ainda está apoiada na crença de raça como algo biológico, pois "raça está mais para a biologia né!" (E38, Branca). Este fato confirma a supremacia do pensamento genealogista na produção de uma inteligibilidade racial que passa a ser o senso comum, pela qual raça significa diferentes espécimes de seres humanos (PROUDFORD; NKOMO, 2006). Esta inteligibilidade genealogista pode ser ilustrada quando E3 (Branca) afirma que raças "seriam características genéticas [...], formato da cabeça. Por exemplo, nordestino, o pessoal fala que tem a cabeça chata. Essas coisas". Na abordagem genealogista o significado de raça produzido nos conduz à visão de raça como algo meramente biológico, e, assim sendo, algo pertencente ao reino da natureza, negando aspectos históricos, políticos, econômicos e sociais na constituição de raças. Vale ressaltar que no campo das ciências sociais o conceito genealogista de raça se estabelece com o nome de primordialismo, onde raça e etnia são aspectos fixos e invariáveis biologicamente e geneticamente determinadas, portanto, com existência a-priori (MUCK, 2011), eliminando aspectos históricos relacionados as relações de poder na definição de raça.

A existência de um poder negligenciado e biologicamente camuflado pelos primordialistas está evidente na própria inteligibilidade que E3 (Branca) tem de raça ao citar o formato da cabeça do nordestino como uma evidencia biológica e natural de que o nordestino seria uma raça específica diferente dos demais brasileiros. Em relação a isso é notório que parte da população situada nas regiões sul e sudeste do Brasil, região em que os sujeitos da pesquisa residem, consideram a população nordestina como inferior e atrasada, estabelecendo relações sociais que utilizam aspectos biológicos para diferenciar, classificar e hierarquizar as pessoas (GILROY, 2001; SCHWARCZ, 2001). O fato de considerar o nordestino inferior e 
atrasado faz com que E3 (Branca) entenda o nordestino como uma raça específica e diferente do restante da população de outras regiões brasileiras, buscando justificar esta diferença no formato da cabeça do nordestino. Esta inteligibilidade sobre o nordestino demonstra como raça atua como um dispositivo organizador do social que cria fronteiras que dividem pessoas entre nós e eles (YUVAL-DAVIS, 2006). Este discurso exemplifica porque raça está para além do biológico, pois apesar de se referir a diferenças fundamentadas em características físicas, de fato manifesta diferenças socialmente construídas, crenças socialmente arraigadas e opressões históricas que são justificadas e naturalizadas como biológicas, mas que estruturam e organizam a sociedade produzindo hierarquias, fronteiras e desigualdades (ACKER, 2006, 2011; LETICHE, 2009), fazendo com que, no senso comum, aspectos de poder sejam camuflados por uma inteligibilidade biológica de que "raça é aquilo que, pelas características físicas, você consegue identificar" (E4, Branca). Por isso raça é um organizador social (APPIAH, 1985; DuBOIS, 1970; TATE, 2005) fluído, formado por interações sociais, ideológicas e culturais complexas (BAINES, 2010) que produz no imaginário social a inteligibilidade de que raça é biológica e natural.

Portanto, um aspecto interessante que deve ser analisado é como o corpo biológico é utilizado como produtor de diferenças entre pessoas no contexto estudado, buscando entender quais partes e características biológicas corporais produzem visibilidade e inteligibilidade racial entre os alunos. Para eles raça é "cor e genética. O índio, ele vem de toda uma genética que no caso aquilo ali eterno, entendeu? Olho puxado, cabelo lisinho. O negro ele vem daquela coisa negra assim. Testosterona ele tem maior. $O$ branco ele tem tendência da melanina da pele ser clara, estas coisas assim" (E2, Branca). Cor de pele, formato de olhos, tipo de cabelo e quantidade de hormônios são utilizados por E2 (Branca) como referenciais para se identificar raça, pois raça para E2 (Branca) são características fenotípicas relacionadas à aparência física (NOGUEIRA, 2007; ROSA, 2014). A principal característica que os alunos utilizam para identificar qual raça alguém pertence "É cor de pele" (E1, Parda). Como uma construção social aspectos históricos e culturais fazem com que cada país estabeleça diferentes lógicas e padrões, mesmo que ancorados em aspectos biológicos, sobre o que seja raça em um determinado tempo e espaço (ACKER, 2011; HALL, 1996), produzindo toda uma inteligibilidade de que os critérios biológicos para se identificar uma raça sejam neutros, iguais, estáveis e imutáveis em qualquer lugar e tempo do globo, ou, como E2 (Branca) afirma "eterno". A inteligibilidade de raça como sendo eterna demonstra como o biológico é utilizado pelos primordialistas para se construir o sentido de raça como algo fixo e invariável, ou seja, com existência a-histórica e a-priori (MUCK, 2011). Entretanto, a crença presente no imaginário social de que raça sempre existiu (DuBOIS, 1970) ao invés de ser algo construído, é uma produção dos processos de racialização, ou seja, um complexo instável produtor de sentidos sociais que produz raças como naturais e onipresentes (APPIAH, 1985; TATE, 2005). Raça como algo biológico é uma construção histórica, política e social que pode ser constatada pelas diferenças entre Estados Unidos e Brasil sobre como o biológico atua na definição de raça, mesmo estando ambas as construções apoiadas em características biológicas. No contexto norte americano a construção social de raça é fundamentada em aspectos genótipos (one drop blood), enquanto no caso brasileiro é fundamentada em aspectos fenotípicos (cor de pele e tipo de cabelo, entre outros), demonstrando o contingenciamento social, político, econômico e histórico do conceito de raça.

É, mas aqui no Brasil as pessoas não querem saber da história da pessoa [ascendência da pessoa], eles olham a cor da pele. [..] Se você é negro e tem a cor da pele escura você é negro. Na nossa família a gente fala: ei mais preto. A gente chama o outro de mais preto para diferenciar um do outro [...]. Na minha família tem 
mulatos, tem negros. A minha irmã tem três filhos, tem um que é mulato, tem um mais clarinho e outro que é branco. Este branco é discriminado desde criança, pois as pessoas acham que ele é adotado e quando minha irmã estava com ele achavam que ela era a babá dele (E11, Negra).

Desta forma, raça são diferenças culturais, raciais e históricas manifestas em práticas sociais disfarçadas e justificadas por diferenças físicas, pela qual sentidos são produzidos e fundamentados no corpo, mas que não pertencem ao corpo, mas sim a uma construção discursiva social histórica (ACKER, 2011; APPIAH, 1985; GILROY, 2001; SWAN, 2010). Sociedades onde prevalece o preconceito de marca tendem a valorizar o surgimento de categorias raciais intermediárias entres os polos branco-negro em função da cor da pele, conforme declarado por E11 (Negra). Já sociedades onde o preconceito de origem prevalece tendem a ser segregacionistas e menos flexíveis ao surgimento de novas categorias raciais, pois o pertencimento de uma pessoa na categoria negro ou branco não está atrelado a cor de sua pele, mas na presença, ou não, em sua árvore genealógica de miscigenação com negros/índios. Na sociedade brasileira prevalece o preconceito de marca, conforme verificado por E11 (Negra) ao relatar que, devido ao fato de sua irmã ser negra e ter um filho branco, as pessoas consideram que ela seja babá e não mãe da criança. Assim, busca-se entender no próximo tópico deste artigo como a miscigenação brasileira e a construção de categorias intermediárias e flexíveis influenciam na inteligibilidade que os alunos de administração têm sobre o pertencimento a uma identidade racial e sobre a noção de original.

\subsection{Miscigenação e Pertencimento: ambiguidade e incompletude de raça}

O Brasil é considerado o país com maior grau de miscigenação no mundo (DEGLER, 1971) o que colabora com a criação de um sistema de categorização racial mais fluído que o norte americano (MUCK, 2011; SANSONE, 1996). A classificação racial no Brasil ocorre em torno da cor de pele, formando terminologias e normas que refletem relações sociais históricas, existindo 36 cores diferentes que são utilizadas no processo de classificação racial (SANSONE, 1996). A miscigenação racial brasileira foi, inclusive, fomentada no passado, pois a miscigenação com brancos era vista como uma forma de regenerar os negros e mestiços que representavam raças atrasadas e inferiores, acreditando-se que o branqueamento seria uma forma de evolução de raças inferiores (LACERDA, 1912). O alto grau de miscigenação em uma sociedade colonial em que raça é definida como um aspecto fenótipo fundamentado em características físicas, principalmente cor de pele, faz com que os sujeitos sintam suas identidades raciais como um local onde diversas fronteiras se encontram (ANZALDÚA, 1987).

$\mathrm{Na}$ minha família tem negro, tem índio, português na minha descendência [sic]. Eu acho que o Brasil hoje ... é isso ... é tipo ... não existe, não existe uma raça, uma 'cor' [faz gesto de sinal de aspas quando pronuncia a palavra cor] pro Brasil. Não existe. Hoje em dia é tudo misturado e [...] as pessoas eu acho que ainda não conseguiram entender isso, compreender isso, que o Brasil ele não tem um .... um ... como o europeu que é tudo branquinho lá, nariz grande, essas coisas assim. Aqui não tem isso. [...]. Então as pessoas, às vezes querem colocar: não, Brasil é povo de negros, o Brasil é um povo disso, daquilo, e não é, porque é tudo. [...] Todo mundo tem uma mistura [...] (E8, Negra). 
E8 (Negra) afirma que não existe no Brasil uma raça original, justificando tal afirmação na crença que a miscigenação faz com que não exista uma raça pura e sem misturas. O discurso de E8 (Negra) novamente demonstra a importância de aspectos fenotípicos na construção da inteligibilidade de raça nas práticas sociais brasileiras, pois o sentido de raça ganha significado para E8 (Negra) na cor da pele e tamanho do nariz. Vale ressaltar novamente que diferentes formas de divisão identitárias, como identidades de raça, tendem a ser naturalizadas e consideradas como sendo um aspecto biológico, produzindo um discurso de naturalização que objetiva homogeneizar identidades e tratar pessoas como se possuíssem um atributo particular biológico específico que a fariam pertencer a uma determinada identidade (COHEN, 1988; YUVAL-DAVIS, 2006). No caso brasileiro o atributo biológico particular principal, mas não único, para definir raça, é cor da pele. Assim, apesar de a cor da pele ser considerada por E8 (Negra) o atributo biológico definidor de raça, a importância e o status que cor ocupa para a significação de raça é uma construção social constituída pelos diversos discursos que circulam em um determinado tempo e espaço e produzem a materialidade neste contexto específico. Discursos definem o que pode ser dito, o que é inteligível, bem como os sentidos produzidos sobre o que é dito, produzindo a realidade e constituindo a visão e os sentidos que temos sobre algo (BENDL, 2005).

Portanto, cor da pele atua como um espaço aberto (BHABHA, 1990) e uma fronteira (ANZALDÚA, 1987) que, apesar de aparentemente tentar camuflar por meio de seu conteúdo biológico aspectos culturais, políticos, econômicos, históricos e sociais relacionados à raça, acaba trazendo consigo estes aspectos, mesmo que de forma postergada, indireta e camuflada. Em outras palavras, cor de pele é o significante pelo qual aspectos econômicos, políticos, sociais, históricos e culturais que envolvem a construção de raças ganham materialidade para os alunos de administração, pois relacionam a cor da pele à presença de determinados aspectos culturais e formas de se viver, acrescentando que a cor da pele, ao definir a raça a que alguém pertence, também determina "a identidade cultural de uma pessoa. Definida por hábitos, religiões" (E32, Branca); constitui o "Conjunto de crença e valores" (E33, Branca) e o "Modo de vida" (E37, Parda) dos sujeitos.

Outro aspecto interessante presente no discurso de E8 (Negra) é a crença de que existiria uma raça originária e pura, o europeu, enquanto que no Brasil não existiria pureza de raças devido à alta miscigenação: "[...] Hoje em dia é tudo misturado e [...] as pessoas eu acho que ainda não conseguiram entender isso, compreender isso, que o Brasil ele não tem um .... um ... como o europeu que é tudo branquinho lá, nariz grande, essas coisas assim [...]“ (E8, Negra). Tal discurso demonstra como fomos e somos ainda colonizados diariamente e que processos de colonização persistem e atuam até os dias de hoje. Os processos de racialização e os códigos raciais vigentes foram confeccionados pelo poder colonial e imperial (GILROY, 2001; GUILLAUMIN, 1995; PRASAD, 2006; WALTON; CALIENDO, 2011) pelos quais o europeu é representado como sendo superior, puro, história da humanidade e origem do mundo (KALONAITYTE, 2010; PRASAD, 2006) e, consequentemente, possuidor de uma raça originária, estável, fundadora, essencial e pura. Por isso para Spivak (1988) os processos de racialização contemporâneos produzem o europeu como o Sujeito escrito em maiúsculo, enquanto que o sujeito colonial é produzido como o Outro, possuidor de uma identidade precária. O colonizado constitui-se como sujeito subalterno e não é considerado como sujeito universal, estável, essencial e puro, mas sempre como um sujeito heterogêneo, misturado e precário, mesmo dentro de sua própria cultura (COSTA; ÁVILA, 2005; SPIVAK, 1988), conforme enunciado a seguir: "Meu pai tinha uma avó que era negra e a outra avó dele era índia. A família de minha mãe o pai dela é de origem italiana a mãe dela metade é de origem italiana, mas tem parentes negros também, é bem misturado" (E32, Branca). 
Atributos raciais constituídos por processos de racialização são utilizados para a construção de fronteiras políticas que diferenciam o Sujeito (europeu) do Outro (não europeu), estabelecendo quem é normal e quem é o exótico e diferente, atribuindo quem é possuidor de determinados recursos e quem é o sujeito falho não detentor destes recursos (YUVAL-DAVIS, 2006). Portanto, apesar de todas as formas de identidades serem precárias (BENDL; FLEISCHMANN, 2008; BUTLER, 1993b; COOPER, 2001; LASTA; HILLESHEIM, 2014), inclusive identidades raciais (TATE, 2005), sejam elas europeias ou não, apenas o Outro (não europeu) constitui-se nesta relação de poder racializada como o incompleto e o precário. Vale ressaltar que o original (europeu) também não é essencial, puro ou acabado, mas também sempre incompleto e sujeito a mudanças (BHABHA, 1990), pois tanto Europeus quando colonizados não possuem uma essência e constituem-se mutuamente em um jogo de diferenças em que as fronteiras se constituem em espaço no qual um contém o outro (ANZALDÚA, 1987) ao ponto de Bhabha $(1998$, p. 36) afirmar que o

\footnotetext{
'originário' está sempre aberto à tradução [...] nunca tem um momento anterior totalizado de ser ou de significação - uma essência. E o que isso de fato quer dizer é que as culturas só são constituídas em relação a essa alteridade interna à sua própria atividade formadora de símbolos que as faz estruturas descentradas [...].
}

Raça constitui-se como fronteiras onde são criados espaços psicológicos, econômicos, vivenciais e culturais, dentre outros, pelos quais as diferenças se afetam mutuamente, "onde duas ou mais culturas beiram uma a outra, onde pessoas de diferentes raças ocupam o mesmo território, onde as classes mais baixas, baixas, médias e altas se tocam" (ANZALDÚA, 1987, p. 17). Estas fronteiras ao mesmo tempo se tocam e se separam, tornando seus limites borrados (TYLER, 2009). Esta ontologia da interconectividade faz com que raça seja um produto de cruzamentos (ANZALDÚA, 1987) que gera uma sensação de ambiguidade, de desconforto e de posições multifacetadas, conforme E28 (Índia/Amarela) afirma: "Ah... Raça não sei! Eu acho que é .... É porque tipo eu sempre fico em dúvida. Minha mãe é índia e eu me considero meio índia ou amarelo, qualquer um dos dois!” (E28, Índia/Amarela). Portanto, conforme E28 (Índia/Amarela) evidencia em seu discurso, raça se constitui como um espaço entre-lugares da diferença com mestiçagens múltiplas (COSTA; ÁVILA, 2005), uma posição desconfortável, uma fronteira borrada.

A angústia expressa no discurso de E28 (Índia/Amarela) em sua busca pela identificação de sua raça demonstra a constante necessidade de negociação de sua posição identitária ao declarar que não sabe com certeza se é índia, amarela ou branca, fazendo com que se sinta entre fronteiras e ocupe um espaço in-between (BHABHA, 1994, 1996; TATE, 2005). Este espaço é denominado por BHABHA $(1990,1998)$ de híbrido, ressaltando-se que o híbrido não pode ser visto como uma nova identidade ou uma mistura genética de raças diferentes (BHABHA, 1990; TATE, 2005), mas um espaço pelo qual "uma identificação que surge na luta sobre posições dentro dos discursos. É constituída por discursos de eu/outro e também vem a constituir esses discursos" (TATE, 2005, p. 25, tradução nossa), ou seja, híbrido é um processo constante de negociação de identificação identitária, dentro do qual a cor da pele atua como uma fronteira (TATE, 2005). Este constante processo de negociação cultural pelo qual a pele atua como fronteira na luta e busca por se posicionar diante dos diversos discursos raciais dentro de uma lógica eu/outro está presente nos discursos a seguir: "Minha mãe é branca de olhos verdes e meu pai é negro. Assim, eu não tenho a árvore genealógica certinho, mas tem europeu" (E35, Negra) e "Minha bisavó é negra, minha avó é negra, meu avô italiano, meu pai italiano, meu irmão italiano" (E5, Branca). 
Assim, o híbrido é a negação da existência do sujeito racial original e essencial, seja ele branco europeu, índio latino-americano, mestiço, pardo ou negro, pois todas culturas estão sempre em um processo continuo de hibridade (BHABHA, 1990; TATE, 2005). O híbrido é um processo de identificação operado por meio da alteridade, ou seja, um processo de se identificar e se posicionar por meio do outro, fazendo com que o sujeito seja sempre ambivalente (BHABHA, 1990), ambivalência esta manifesta nos discursos a seguir: "Tem uma parte polonesa e meu pai é moreno escuro" (E37, Parda); "Eu sou o mais moreno da família e a outra parte é japonesa" (E36, Branca); "Eu tenho minha avó negra e meu avô italiano, ai acabou que uma irmã é de cabelo liso, outra de cabelo cacheado. Aí eu tenho o cabelo mais ou menos. Aí é uma mistura só, né” (E6, Parda). Estes entrevistados (E6, E36 e E37) demonstram em seus discursos a identificação operada por meio de uma noção eu/outro na qual o Outro é possuidor de uma essência pura e original: polonês versus moreno escuro (E37), japonês versus moreno (E36), negro versus italiano, cabelo liso versus cabelo cacheado (E6).

Aliás, o discurso de E36 (Branca) demonstra claramente esta angústia e fluidez de se posicionar e se identificar plenamente em uma relação eu/outro, pois E36 (Branca) se autodeclarou de raça branca, mas quando em seu discurso se compara com o restante da família de origem japonesa se identifica como tendo raça morena, mostrando que o sujeito sempre fala e age por meio de uma multiplicidade eu/outro que o constitui como sujeito, tornando a hibridade um espaço liminar onde identificação em uma identidade é um processo de interação simbólica que, ao mesmo tempo, produz diferença e igualdade tanto entre identidades diferentes, quanto dentro de mesma categoria identitária (BHABHA, 1994), fazendo com que o híbrido torne-se, ao mesmo tempo, igualdade e diferença, uma ambiguidade que nunca pode ser solucionada ou acabada (TATE, 2005), rompendo com a ideia de uma identidade racial essencial e original (YOUNG, 1995). Estas contradições produzem todas as raças como sendo híbridas, não sendo originais. Mesmo apresentando cor de pele branca e se autodeclarando como branco E36 (Branca), ela não se identifica como sendo um original, pois entende que o original não está finalizado ou completo em si mesmo. A diferença e igualdade produzida dentro de uma mesma categoria de identidade racial pode ser exemplificada nos discursos a seguir:

Eu tenho algumas gírias que são mais ligadas à cultura negra, mais forte. O que me afasta [da raça negra] é eu já estar aqui [na universidade] é um pouco diferente né, federal, é uma coisa mais incomum (E35, Negra).

O que eu tenho em comum, professor, com a cultura negra é a vontade de trabalhar e também não vejo tão diferente deles assim. Falo gírias, às vezes, me identifico muito com a raça negra sim. O que me diferencia é estar aqui na faculdade em si e que outras pessoas não poderão estar (E37, Parda).

Apesar de se autodeclarar parda e não negra, E37 (Parda) afirma que tem traços culturais que julga pertencerem à cultura negra, o que a faz se identificar como sendo negra: vontade de trabalhar e gírias empregadas por negros. Mas, ao mesmo tempo, ela alega, similarmente a E35 (Negra), que o fato de estar estudando em uma universidade federal faz com que se afaste de uma identificação completa como negra, pois considera que a universidade federal não é um espaço para negros. Isto demonstra como uma determinada raça, ao mesmo tempo, produz diferença e igualdade (TATE, 2005). Ao mesmo tempo em que E37 (Parda) e E35 (Negra) se identificam como negras, elas também se desidentificam ao considerarem que têm uma característica que não faz parte da identidade negra: frequentar ensino superior em universidade federal. Desta forma, o híbrido torna-se ao mesmo tempo 
ruptura e reconciliação com a noção essencial de raça, pois ao mesmo tempo em que identidades raciais são fluídas, ambivalentes e incompletas, elas são dependentes de um essencialismo presente nas práticas cotidianas que contingencia as possibilidades interacionais entre raças diferentes, produzindo em uma mesma identidade racial a sensação de diferença e igualdade (TATE, 2005), pertencimento e não pertencimento, identificação e desidentificação (BUTLER, 1990, 1993a). Portanto, identidades de raça são atos performativos produzidos pela continua repetição de normas discursivas que circulam em nossas práticas diárias, produzindo uma sensação de que raças são essenciais, apesar de não existir uma raça essencial ou original, pois identidades de raça são paródias, fantasias de uma fantasia (BUTLER, 1990, 1993a), uma ilusão de raça essencial, pois todas as raças são incompletas.

\section{CONSIDERAÇÕES FINAIS}

A inteligibilidade de raça produzida pelos processos de racialização estabelece no imaginário social dos alunos de administração que raça é algo que sempre existiu exatamente por se referir a uma característica meramente biológica. Assim, o primordialismo produz nos alunos uma crença de que raça é algo natural, biológica, a-histórica e estável. Entretanto, os mesmos discursos dos alunos também permitem verificar que raça funciona como um organizador social, estabelecendo fronteiras nós/eles, demonstrando que as diferenças físicas são utilizadas apenas para justificar e camuflar relações de poder, hierarquias sociais e opressões históricas. Os discursos dos alunos demonstram como aspectos fenotípicos estruturam e organizam a sociedade brasileira em termos raciais, produzindo no senso comum a crença de que raça significa cor de pele, tipo de cabelo, formato do nariz, entre outras características fenotípicas. Mas, de fato, esta inteligibilidade fenotípica sobre raça esconde desigualdades sociais e estratégias políticas. Aspectos coloniais moldaram e contingenciaram a inteligibilidade de raça no contexto brasileiro.

O alto grau de miscigenação racial no Brasil favoreceu o estabelecimento de códigos raciais específicos, como o preconceito de marca. A miscigenação favoreceu a crença de que haveria uma raça original europeia e que as demais raças seriam não originais. Entretanto, isso manifesta o poder colonial que ainda atua contemporaneamente, colonizando o nosso imaginário social sobre raça, ao estabelecer o europeu como o Sujeito maiúsculo e as demais raças como os Outros. Contudo, como pode ser verificado nas análises, ao mesmo tempo que os alunos de administração se apoiam em uma visão essencial de raça, eles também rompem com essa essência. Aliás o híbrido é exatamente o espaço onde ocorrem, ao mesmo tempo, reconciliação e rompimento com a noção essencial de identidade racial, demonstrando que todas as identidades raciais são instáveis, incompletas e não originais, pois apesar de os alunos utilizarem características físicas fenotípicas na definição de raça, estas características não são suficientes para fornecerem uma garantia estável de pertencimento racial.

Nesse sentido, a desconstrução de hierarquias sociais depende exatamente da problematização da inteligibilidade primordialista de raça. Problematizar a inteligibilidade genealogista/primordialista permite expor os aspectos políticos, sociais, econômicos e históricos que contingenciam a construção de raça no contexto brasileiro. Somente com a evidenciação da presença destes aspectos na construção de raça é que desigualdades sociais poderão ser combatidas e desnaturalizadas. Exatamente por isso que é de extrema importância que o debate sobre raça faça parte da formação do administrador, pois assim os alunos de administração poderão estabelecer relações entre raça e poder ao observarem o conteúdo 
político e organizador de raça na produção de desigualdades sociais, ao invés de uma característica biológica meramente fenotípica.

\section{REFERÊNCIAS}

ACKER, J. Inequality regimes gender, class, and race in organizations. Gender \& Society, v. 20, n. 4, p. 441-464, 2006.

ACKER, J. Theorizing gender, race and class in organizations. In: JEANES, E; KNIGHTS, D.; MARTIN, P. Y. (Eds.). Handbook of Gender, Work and Organization. West Sussex: Wiley-Blackwell, 2011. p. 65-80.

AINSWORTH, S.; HARDY, C. Discourse and identities. In: GRANT, D.; HARDY, C.; OSWICK, C.; PUTNAM, L. (Eds). The Sage Handbook of Organizational Discourse. London: SAGE Publications Ltd, 2004. p.153-173.

ANZALDÚA, G. Borderlands/la frontera: the new mestiza. San Francisco: Aunt Lute Books, 1987.

APPIAH, A. The uncompleted argument: DuBois and the illusion of race. Critical Inquiry 1985.

BAINES, D. Gender mainstreaming in a development project: intersectionality in a postcolonial un-doing? Gender, Work and Organization, v. 17, n. 2, p. 119-149, 2010.

BENDL, R.; FLEISCHMANN, A. Diversity management discourse meets queer theory. Gender in Management: An International Journal, v. 23, n. 6, p. 382-394, 2008.

BENDL, R. Revisiting organizational theory: integration and deconstruction of gender and transformation of organization theory. Frankfurt am Main, Berlin: Lang, 2005.

BHABHA, H. The third space: interview with Homi Bhabha. In: RUTHERFORD, J. (Ed.). Identity: community, culture, difference. London: Lawrence and Wishart, 1990. p.207-221.

BHABHA, H. The location of culture. London; New York: Routledge, 1994.

BHABHA, H. 'Unpacking my library ... again'. In: CHAMBERS, I.; CURTI, L. (Eds), The Postcolonial Question - Commom Skies, Divided Horizons. Routledge: London, 1996. p. 199211.

BHABHA, H. O local da cultura. Belo Horizonte: UFMG, 1998.

BUTLER, J. Gender Trouble: feminism and the subversion of identity. New York and London: Routledge, 1990.

BUTLER, J. Critically Queer, GLQ, v. 1, p. 17-32, 1993a.

BUTLER, J. Bodies that matter: on the discursive limits of "sex". New York: Routledge, $1993 b$. 
BUTLER, J. The psychic life of power: theories in subjection. Stanford: Stanford University Press, 1997.

CASTRO, E. Vocabulário de Foucault: um percurso pelos seus temas, conceitos e autores. Belo Horizonte: Autêntica, 2009.

CARNEIRO, A. S. A construção do outro como não-ser como fundamento do ser. 2005. 339 f. Tese (Doutorado em Educação) - Programa de Pós-Graduação em Educação, Universidade de São Paulo, São Paulo, 2005.

COHEN, P. 'The perversions of inheritance'. In: COHEN, P.; BAINS, H. S. (Eds). MultiRacist Britain. London: Macmillan, 1988.

COOPER, R. Interpreting mass: collection/dispersion. In: LAW, N.; MUNRO, R. (Eds), The consumption of mass. Oxford: Blackwell, 2001. p. 16-43.

COSTA, C. D. L.; ÁVILA, E. Gloria Anzaldúa, a consciência mestiça e o "feminismo da diferença." Revista Estudos Feministas, v. 13, n. 3, p. 691-703, 2005.

COX, T.; NKOMO, S. Invisible men and women: a status report on race as a variable in organization behavior research. Journal of Organizational Behavior, v. 11, n. 6, p. 419-31, 1990.

DEGLER, C. Neither black nor white: slavery and race relations in Brazil and the United States. New York: Macmillan, 1971.

DuBOIS, W. E. B. W.E.B. Du Bois speaks. In: FONER, P. (Ed.). Speeches and addresses. 1890-1919. New York: Pathfinder Press, 1970.

ELY, R. J.; MEYERSON, D. E. Advancing gender equity in organizations: the challenge and impor- tance of maintaining a gender narrative. Organization, v. 7, n. 4, p. 589-608, 2000.

FOUCAULT, M. L'ordre du discours. Leçon inaugurale au Collège de France prononcèe le 2 décembre 1970. Paris: Éditions Gallimard, 1970.

FOUCAULT, M. Estratégia, poder-saber. Rio de Janeiro: Forense Universitária, 2010.

GILROY, P. Against race: imagining political culture beyond the color line. Boston: Harvard University Press, 2001.

GODIM, S. M. G. Grupos focais como técnica de investigação qualitativa: desafios metodológicos. Paidéia, v. 12, n. 24, p. 149-161, 2003.

GUILLAUMIN, C. The specific characteristics of racist ideology. In: MILES, R (Ed). Racism, sexism, power, and ideology: Colete Guillaumin. London and New York: Routledge, 1995. p. 29-60.

HALL, S. Encoding, decoding. In: DURING, S. (Ed.). The cultural studies reader. London and New York: Routledge, 1993. p.507-517. 
HALL, S. "New Ethnicities.” In: HALL, S.; MORLEY, D.; CHEN, K. H. (Eds.), Stuart Hall: critical dialogues in cultural studies. London: Routledge, 1996. p. 441-449.

HARDING, N.; FORD, J.; FOTAKI, M. Invited contribution 'Is 'F' word still dirty? Twenty years of feminism and gender studies in Organization and feminist journals'. Organization, v. 20, n. 1, p. 51-65, 2013.

HOLVINO, E. Intersections: the simultaneity of race, gender and class in organization studies. Gender, Work and Organization, v. 17, n. 3, p. 248-277, 2010.

JONES, D.; STABLEIN, R. Diversity as resistance and recuperation: critical theory, poststructuralist perspectives and workplace diversity. In: KONRAD, A. M.; PRASAD, P.; PRINGLE, J. K. (Eds.), Handbook of Workplace Diversity (p. 145-166). London: SAGE Publications, 2006.

KALONAITYTE, V. The case of vanishing borders: theorizing diversity management as internal border control. Organization, v. 17, n. 1, p. 31-52, 2010.

KONRAD, A. M. Special issue introduction: defining the domain of workplace diversity scholarship. Group \& Organization Management, v. 28, n. 1, p. 4-17, 2003.

LACERDA, J. B. O congresso universal das raças reunido em Londres. Rio de Janeiro: Papelaria Macedo, 1912.

LASTA, L. L.; HILLESHEIM, B. Políticas de inclusão escolar: produção da anormalidade (School inclusion politics: the production of abnormallity). Psicologia \& Sociedade, v. 26, n. especial, p. 140-149, 2014.

LETICHE, H. Doubling: there's an escape from commodification ...? Society and Business Review, v. 4, n. 1, p. 8-25, 2009.

MUCK, W. Colonialism/postcolonialism. In: CALIENDO, S. M; MCLLWAIN, C. D. (Eds.). The routledge companion to race and ethnicity. London: Routledge, 2011. p. 29-37.

NOGUEIRA, O. Preconceito racial de marca e preconceito racial de origem: sugestão de um quadro de referência para a interpretação do material sobre relações raciais no Brasil. Tempo Social, v. 19, n. 1, p. 287-308, 2007.

ORLANDI, E. P. Análise de discurso: princípios e procedimentos. Campinas: Pontes, 2005.

PRASAD, A. The jewel in the crown: postcolonial theory and workplace diversity. In: KONRAD, A. M.; PRASAD, P.; PRINGLE, J. K. (Eds.). Handbook of Workplace Diversity. London: SAGE Publications, 2006. p. 121-144.

PROUDFORD, K. L.; NKOMO, S. Race and ethnicity in organizations. In: KONRAD, A. M.; PRASAD, P.; PRINGLE, J. K. (Eds.). Handbook of Workplace Diversity. London: SAGE Publications, 2006. p. 323-344.

ROSA, A. R. Relações raciais e estudos organizacionais no Brasil. Revista de Administração Contemporânea, v. 18, n. 3, p. 240-260, 2014. 
SANSONE, L. Nem somente preto ou negro: o sistema de classificação racial no Brasil que muda. Afro-Ásia, v. 18, p. 165-187, 1996.

SWAN, E. "A testing time, full of potential?" Gender in management, histories and futures. Gender in Management: An International Journal, v. 25, n. 8, p. 661-675, 2010.

SCHWARCZ, L. M. Racismo no Brasil. São Paulo: Publifolha, 2001.

SCHWARCZ, L. M. Nem preto nem branco, muito pelo contrário: cor e raça na sociabilidade brasileira. São Paulo: Claro Enigma, 2012.

SPIVAK, G. C. Can the subaltern speak? In: NELSON, C.; GROSSBERG, L. (Eds.). Marxism and the interpretation of culture. Urbana: University of Illinois Press, 1988. p. 271313.

TATE, S. A. Black skins, black masks: hybridity, dialogism, performativity. Aldershot: Ashgate Publishing Limited, 2005.

TYLER, J. A. Moving beyond scholar-practitioner binaries: exploring the liminal possibilities of the borderlands. Advances in Developing Human Resources, v. 11, n. 4, p. 523-535, 2009.

VIEIRA, M.; CALDAS, M. Teoria crítica e pós-modernismo: principais alternativas à hegemonia funcionalista. Revista de Administração de Empresas, v. 46, n. 1, p. 59-70, 2005.

WALTON, F. C.; CALIENDO, S. M. Origins of the concept of race. In: CALIENDO, S. M.; McLLWAIN, C. D. (Eds.). The routledge companion to race and ethnicity (p. 3-11). London: Routledge, 2011.

YOUNG, R. Colonial desire: hybridity in theory, culture and race. London: Routledge, 1995.

YUVAL-DAVIS. Intersectionality and feminist politics. European Journal of Women's Studies, v. 13, n. 3, p. 193-209, 2006. 